\title{
Effect of Gaseous Atmosphere on Different Supplementation Medium for In Vitro Canine Oocyte Maturation
}

\author{
Noelia González ${ }^{*}, 1$, Lydia Gil ${ }^{1}$, Glenda Rios ${ }^{3}$, Jesica Canizo ${ }^{3}$, José Ignacio De Blas ${ }^{2}$ and \\ Ricardo Alberio ${ }^{3}$
}

\author{
${ }^{1}$ Reproduction and Obstetric Unit, Veterinary Faculty, Saragossa University, Spain \\ ${ }^{2}$ Infectious Diseases Unit, Veterinary Faculty, Saragossa University, Spain \\ ${ }^{3}$ Biotechnology Reproduction Laboratory, INTA Balcarce, Argentina
}

\begin{abstract}
The aim of the present research was to verify the influence of two different atmosphere gases $\left(\mathrm{A}: 5 \% \mathrm{CO}_{2}, \mathrm{~B}\right.$ : $5 \% \mathrm{CO}_{2}, 5 \% \mathrm{O}_{2}$ and $90 \% \mathrm{~N}_{2}$ ) on three different maturation media on in vitro maturation (IVM) rates for oocytes from anoestrous and diestrous bitches that were cultured in vitro for $48 \mathrm{~h}$. Oocytes harvested from bitches were selected and allocated into three maturation media groups, cultured in atmosphere A or B. Group 1, oestrous bitch serum; Group 2, bovine serum albumin (BSA), glutamine, cisteamine; Group 3, BSA, estrogen $\left(\mathrm{E}_{2}\right)$, epidermal growth factor (EGF). Progression of nuclear maturation was evaluated under fluorescent microscopy after staining with Hoechst 33342 solution.

The results demonstrated that different maturation media was not influenced by the atmosphere in any case. Group 1 showed the lowest maturation rates in both cases: $4.3 \pm 1.3$ vs $7.3 \pm 2.1$ and $7.9 \pm 2.5$ for groups 1,2 and 3 respectively in atmosphere A $(p \leq 0.5), 0$ vs $7.2 \pm 2.9$ and $9.3 \pm 4.0$ in atmosphere B $(p=0.33)$. Maturation rates were similar among treatments 2 and 3 in both atmospheres, were slightly higher for treatment 3. Moreover, group 1 obtained the highest degeneration rates: $65.5 \pm 7.3$ vs $39.63 \pm 7.1,28.19 \pm 6.4(\mathrm{p}=0.018)$ and $71.43 \pm 12.2$ vs $27.71 \pm 10,25.33 \pm 10.20(\mathrm{p}=0.010)$ for mediums 1,2 , and 3 in atmospheres $\mathrm{A}$ and $\mathrm{B}$ respectively.

Our findings indicate that atmosphere B seems to be more favorable habitat for canine oocytes and independently of gassed, maturation with not controlled supplementation, with estrous bitch serum, is not a good option.
\end{abstract}

Keywords: Canine oocyte, maturation media, incubation environment.

\section{INTRODUCTION}

In vitro reproductive technologies in the domestic bitch would be useful in reproductive management in the future for companion animal, although nowadays the efficiency of in in vitro maturation (IVM) of canine oocytes remains very low [1] over other species in which are well established. Probably this is due to the unique reproductive physiology of bitch, where oocytes are ovulated as immature oocytes at the germinal vesicle stage $(\mathrm{GV})$, and requiring $2-5$ days for completion of the maturation process within the oviduct [2]. The main problem is related with the unknown maturation process, so it is complex to mimic this process in laboratory conditions. Several factors could be taken into account when oocytes are exposed around the time of ovulation, such as hormonal or environment factors. In the bitch, high concentrations of estradiol-17 $\beta \quad\left(\mathrm{E}_{2}\right)$ are present in the follicular fluid of preovulatory follicles. Following ovulation, canine oocytes are also exposed to high $\mathrm{E}_{2}$ concentrations in the oviduct, suggesting that $E_{2}$ plays an important role in the meiotic oocyte maturation [3]. In other

*Address correspondence to this author at the Reproduction and Obstetric Unit, Veterinary Faculty, Saragossa University, Spain; Tel: 34 976761564; Fax: 34 976761612; E-mail: noegorti@unizar.es side, the presence of epidermal growth factor (EGF) in the follicular fluid of developing follicles has been reported in different species, such as the pig [4] and human [5]. Moreover, not only EGF but their receptor mRNA and protein have been found also in oocytes of other species, including pig [6], cow [7] and human [8]. Perhaps EGF regulates oocyte growth, and may be responsible for stimulating nuclear and cytoplasmic maturation. In addition, a significant positive effect of EGF on IVM of oocytes has been reported in various species, including dog [7, 9, 10-12]. Maturation results could be improved, including the media components that protect oocytes against the toxic effect of oxidative damage [13], as cisteamine. It is a critical component amino acid of glutathione (GSH), a thiol tripeptide synthesized by the gammaglutamyl cycle. On other side, adding energy substrates to culture medium is essential for resumption and completion of meiosis in vitro for many mammalian species, so it must be consider in canine oocytes. Energy metabolism plays a significant role in promoting dog oocyte maturation [14], information that will be useful for improving culture systems and get better maturation results. All previous conditions and substances must be considered in an environment that try to mimic oxygen and $\mathrm{CO}_{2}$ tension for maturation, taking into account reactive oxygen species levels, for apoptosis levels control. 
$5 \% \mathrm{CO}_{2}$ is the most common concentration in IVM oocytes studies. In relation with oxygen, high in vitro $\mathrm{O}_{2}$ tensions are associated with enhanced levels of reactive oxygen species and cumulus oocyte complex (COC) apoptosis, so low $\mathrm{O}_{2}$ tension was efficient in reducing apoptosis in canine oocytes [15]. However there are no studies about the influence of nitrogen on canine oocyte maturation. The interaction between media and environment conditions must be considered to improve maturation results, so the aim of the present research was to verify the influence of two different atmosphere gasses $\left(\mathrm{A}: 5 \% \mathrm{CO}_{2}, \mathrm{~B}: 5 \% \mathrm{CO}_{2}, 5 \% \mathrm{O}_{2}\right.$ and $90 \% \mathrm{~N}_{2}$ ) on three different maturation media on in vitro maturation (IVM) rates for oocytes from anoestrous and diestrous bitches that were cultured in vitro for $48 \mathrm{~h}$.

\section{MATERIALS AND METHODS}

\section{Chemicals}

All chemicals in this study were purchased from the Sigma Chemical Company (Sigma, St. Louis, MO, USA), unless stated otherwise.

\section{Oocyte Collection and Maturation}

Following ovariohysterectomy of 39 bitches (anoestrous and diestrus, aged 6-48 months), ovaries inside the ovarian bursa were maintained in physiological saline solution at room temperature $\left(25^{\circ} \mathrm{C}\right)$. Within $2 \mathrm{~h}$ after recovery, ovaries and the ovarian bursa were transported to the laboratory. Ovaries were thinly sliced with a scalpel blade to release the COCs into a Phosphate Buffered Saline (PBS) plus 10\% fetal calf serum (FCS). Selection of COCs was performed under a stereomicroscope, then they were washed three times in tissue culture medium (TCM-199-HEPES) and classified according to the homogeneity of the cytoplasm and the number of layers of cumulus oophorus following classification proposed by Luboni et al. [16]. Oocytes were distributed randomly between the corresponding experimental treatments. Only grade I COCs were placed in a four well culture dish (NUNC) containing $500 \mu$ of the maturation medium covered with mineral oil. The basic culture medium was TCM-199 supplemented with $25 \mathrm{mM}$ Hepes $/ 1$, $50 \mu \mathrm{g} / \mathrm{ml}$ gentamycin, $2.2 \mathrm{mg} / \mathrm{ml}$ sodium bicarbonate and $22 \mu \mathrm{g} / \mathrm{ml}$ pyruvic acid. Different supplementation treatments were: (1) medium with $10 \%$ inactivated oestrous bitch serum, (2) $0.3 \%$ BSA, $500 \mu \mathrm{g} / \mathrm{ml}$ glutamine and $100 \mu \mathrm{M}$ cisteamine or (3) medium supplemented with $0.3 \% \mathrm{BSA}, 2 \mu \mathrm{gr} / \mathrm{ml} \mathrm{E} \mathrm{E}_{2}$ and $10 \mathrm{ngr} / \mathrm{ml}$ EGF. Oocytes were cultured in $500 \mu \mathrm{l}$ well (up to 60 oocytes per well) for $48 \mathrm{~h}$ under mineral oil at $38.5^{\circ} \mathrm{C}$ in a $100 \%$ humidified atmosphere containing two different gasses in air: $5 \% \mathrm{CO}_{2}$ (treatment A) or $5 \% \mathrm{CO}_{2}, 5 \% \mathrm{O}_{2}$ and $90 \% \mathrm{~N}_{2}$ (treatment B).

\section{Assessment of Nuclear Maturation}

At the end of the culture period, the oocytes were denuded by repeated aspiration for the removal of cumulus cells.

Oocytes were then fixed and stained with Hoechst 33342 as described [17]. The degree of nuclear maturation was evaluated through a fluorescence microscope (NIKON BX40F-3). The DNA material of oocytes was classified as being at the germinal vesicle stage (Fig. 1), at the germinal vesicle breakdown stage (Fig. 2), at the metaphase I stage (Fig. 3), and at metaphase II stage (Fig. 4). Oocytes with dispersed chromosomes or chromatin aggregates, as well as those without any chromatin staining, were considered degenerated.

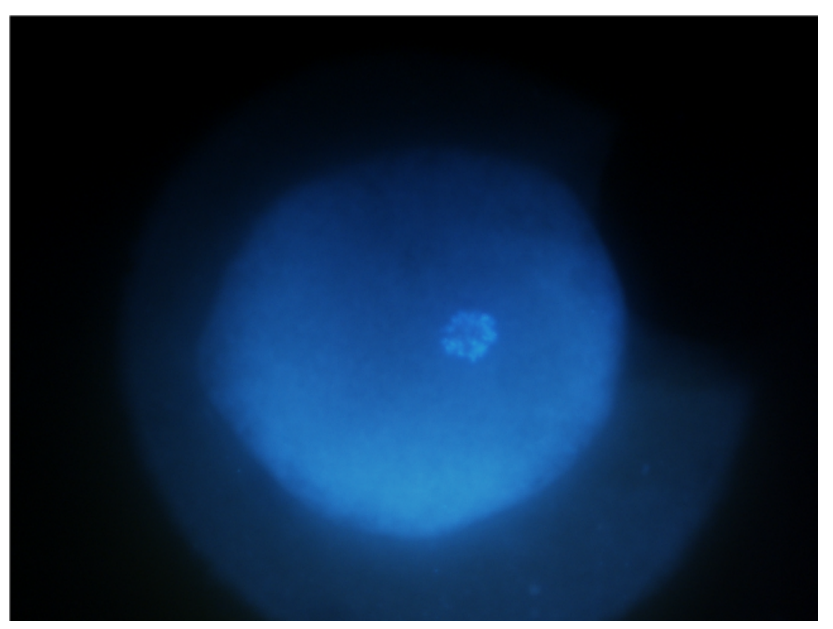

Fig. (1). Germinal vesicle (GV).

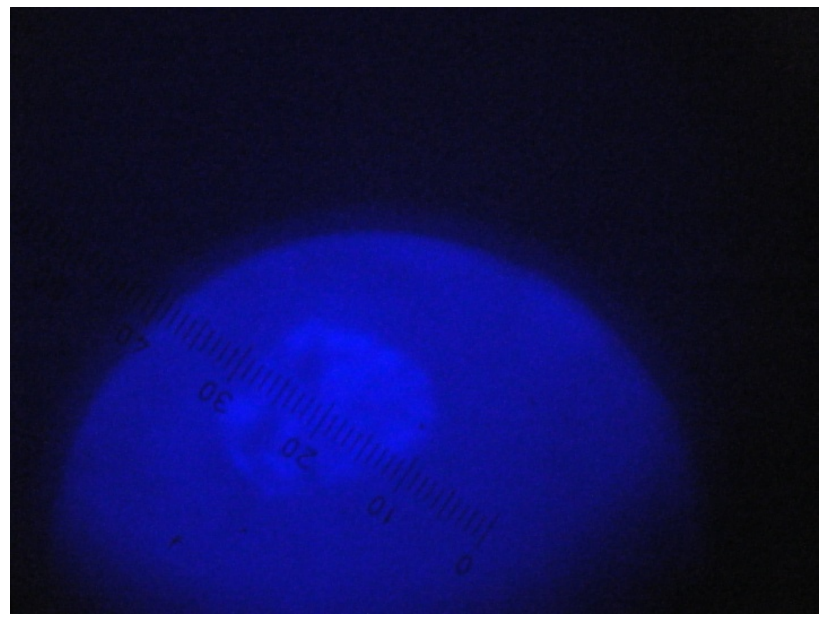

Fig. (2). Germinal vesicle breakdown (GVBD).

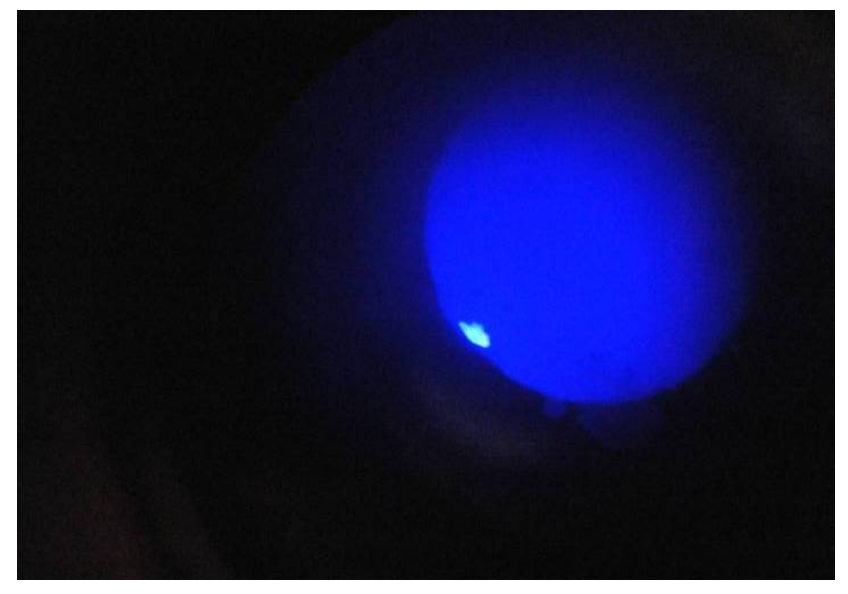

Fig. (3). Metaphase I (I).

\section{Statistical Analyses}

Statistical analyses were carried out with SPSS, version 17.0 for windows. 


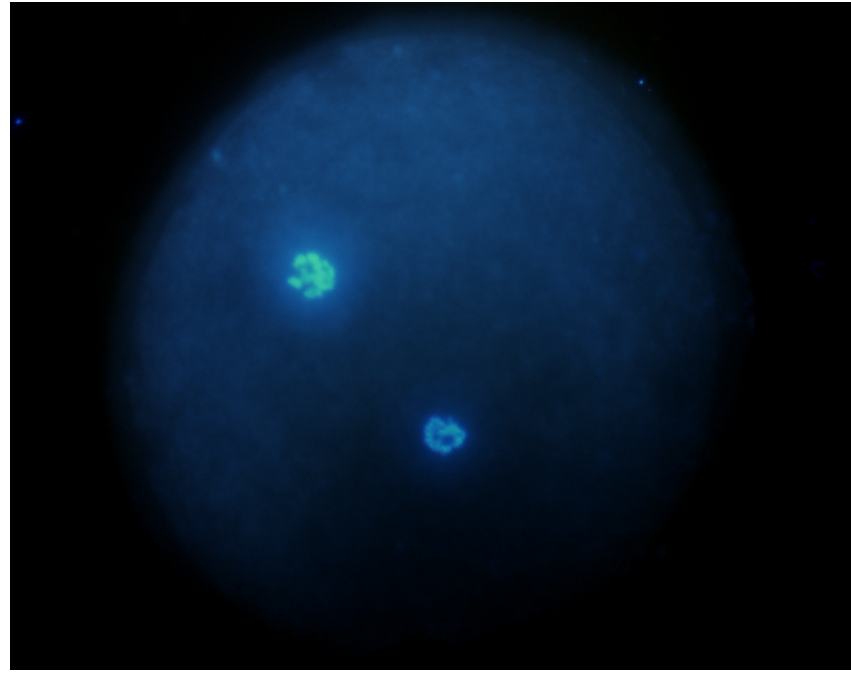

Fig. (4). Metaphase II (MII).

Differences among treatments were analysed using Univariate Analysis of Variance (ANOVA). Data are expressed as the mean \pm SEM. Differences were considered significant when $\mathrm{p}<0.05$.

\section{RESULTS AND DISCUSION}

The main objective of canine oocyte maturation protocols is to mimic in vivo environment and hormonal conditions; it is a key factor for IVM success. In most mammals, preovulatory oocytes develop in an intra-follicular environment dominated by $\mathrm{E}_{2}$ and are ovulated in metaphase II (MII). However, in canids oocyte is exposed to high intrafollicular concentrations of progesterone [18] and lower in oviduct, where maturation is completed.
Poor results of maturation may reflect, at least in part, suboptimal conditions during IVM. Trying to find a good option, in this study two different environment conditions were used for oocyte maturation on three maturation media, to confirm if any of them could improve the results of any maturation media. For the time being no good results are raised with no media, and although there was no influence of any of the environments on them, according to our results maybe this environment could be useful for improving maturation rates.

In this study a total of 668 grade I oocytes were collected from 39 bitches, and were distributed homogeneously in six groups. 468 and 200 oocytes were matured with treatments $\mathrm{A}$ and $\mathrm{B}$ respectively. Inside each treatment, distributed and cultured for $48 \mathrm{~h}$ in the three experimental groups: 116, 164 and 188 for groups 1,2 and 3 in case of treatment A. 42, 75 and 83 for groups 1, 2 and 3 in case of treatment B.

Analysing the results in Tables $\mathbf{1}$ and 2, we can observe that: in germinal vesicle stage, oocytes assessed showed a little significant difference between maturation treatments $(\mathrm{p}<0.059)$, but not in relation with atmosphere environment. Means for A atmosphere were similar, although inferior in case of group 1, with $10 \%$ inactivated oestrous bitch serum supplementation, in both environments.

For oocytes at germinal vesicle break down, there were significant differences among maturation groups inside each atmosphere environment, but no interaction between treatment and atmosphere was found. For A atmosphere there were significant differences $(\mathrm{p}<0.029)$, group 1 was the worst $(12.07 \pm 4.0)$, followed by groups 2 and 3 was the best option, with means almost three times higher. In case of $\mathrm{B}$ atmosphere, means results were similar to environment $\mathrm{A}$ : the worst group 1, and groups 2 and 3 with almost equal

Table 1. Meiotic Stage Results for Different Maturation Mediums, with 5\% $\mathrm{CO}_{2}$ Environment

\begin{tabular}{|c|c|c|c|c|c|}
\hline Stage & $\mathbf{n}$ & Group 1 & Group 2 & Group 3 & p \\
\hline \hline GV & 48 & $4.31 \pm 2.30^{\mathrm{a}}$ & $12.80 \pm 4.09^{\mathrm{a}}$ & $10.11 \pm 2.40^{\mathrm{a}}$ & 0.290 \\
\hline GVBD & 144 & $12.07 \pm 4.01^{\mathrm{a}}$ & $22.56 \pm 5.42^{\mathrm{b}}$ & $38.83 \pm 5.66^{\mathrm{b}}$ & 0.029 \\
\hline MET I & 79 & $13.79 \pm 4.37^{\mathrm{a}}$ & $17.68 \pm 3.78^{\mathrm{a}}$ & $14.89 \pm 3.92^{\mathrm{a}}$ & 0.828 \\
\hline MET II & 35 & $4.31 \pm 1.30^{\mathrm{a}}$ & $7.32 \pm 2.12^{\mathrm{a}}$ & $7.98 \pm 2.57^{\mathrm{a}}$ & 0.524 \\
\hline DEG & 162 & $65.52 \pm 7.36^{\mathrm{a}}$ & $39.63 \pm 7.18^{\mathrm{b}}$ & $28.19 \pm 6.46^{\mathrm{b}}$ & 0.018 \\
\hline
\end{tabular}

${ }^{\mathrm{b}}$ Different superscripts between groups indicate significant difference $(\mathrm{P}<0.05)$.

Group 1: oestrous bitch serum medium supplemented. Group 2: BSA, glutamine and cisteamine medium supplemented. Group 3: BSA, E 2 , EGF medium supplemented. GV: germinal vesicle, GVBD: germinal vesicle break down, MET I: metaphase I, MET II: metaphase II, DEG: degenerated.

Table 2. Meiotic Stage Results for Different Maturation Mediums, with $5 \% \mathrm{CO}_{2}+5 \% \mathrm{O}_{2}+90 \% \mathrm{~N}_{2}$ Environment

\begin{tabular}{|c|c|c|c|c|c|}
\hline Stage & n & Group 1 & Group 2 & Group 3 & p \\
\hline \hline GV & 19 & $*^{\mathrm{a}}$ & $14.46 \pm 5.74^{\mathrm{a}}$ & $9.33 \pm 3.79^{\mathrm{a}}$ & 0.139 \\
\hline GVBD & 63 & $14.29 \pm 6.67^{\mathrm{a}}$ & $36.145 \pm 7.62^{\mathrm{b}}$ & $36.00 \pm 8.96^{\mathrm{b}}$ & 0.021 \\
\hline MET I & 33 & $14.29 \pm 7.26^{\mathrm{a}}$ & $14.46 \pm 5.32^{\mathrm{a}}$ & $20.00 \pm 6.20^{\mathrm{a}}$ & 0.577 \\
\hline MET II & 13 & $*^{\mathrm{a}}$ & $7.229 \pm 2.98^{\mathrm{a}}$ & $9.333 \pm 4.07^{\mathrm{a}}$ & 0.338 \\
\hline DEG & 72 & $71.42 \pm 12.29^{\mathrm{a}}$ & $27.71 \pm 10.08^{\mathrm{b}}$ & $25.33 \pm 10.23^{\mathrm{b}}$ & 0.010 \\
\hline
\end{tabular}

${ }^{\mathrm{a}, \mathrm{b}}$ Different superscripts between groups indicate significant difference $(\mathrm{P}<0.05)$. *: any oocytes were observed.

Group 1: oestrous bitch serum medium supplemented. Group 2: BSA, glutamine and cisteamine medium supplemented. Group 3: BSA, E 2 , EGF medium supplemented. GV: germinal vesicle, GVBD: germinal vesicle break down, MET I: metaphase I, MET II: metaphase II, DEG: degenerated. 
values, around triple that group 1.

In case of oocytes that reached stage of metaphase I, they didn't show significant differences among maturation medium or atmosphere environment, means for environment A were around $15.00 \pm 0.00$, with the best result for group 2 $(17.68 \pm 3.78)$. In environment $B$ was the same situation, with best results for group $3(20.00 \pm 6.20)$. There is no interaction between media and atmosphere.

Maturation medium or atmosphere environment did not interfere oocytes ability to reach metaphase II stage, although medium 3 showed the trend of better results and the worst was medium $1(p<0.145)$ in both atmosphere environment, atmosphere B was slightly better. For atmosphere A, group 1 mean was half of the other groups, in atmosphere B no results were obtained for group 1, and group 3 still maintains the best mean.

Environmental factors, among which are oxygen tension and lack of protective antioxidant mechanisms present in follicular, oviductal and uterine environments [19] act as variables influencing the generation of oxidative stress and may represented the responsible of poor maturation rates. Nevertheless, we can see a positive tendency for B atmosphere, which recreates better maturation condition for canine oocytes. Im et al. [20] demonstrated that in porcine embryo nuclear transfer, the better results of in vitro embryo development were obtained with $5 \% \mathrm{CO}_{2}, 5 \% \mathrm{O}_{2}$ and $90 \%$ $\mathrm{N}_{2}$, not with $5 \% \mathrm{CO}_{2}$. Different culture medium, NCSU-23, Porcine Zygote Medium-3 and Beltsville Embryo Culture Medium-3 were used, three of them defined media and NUCSU- 23the simplest medium, was the best option.

In the end, there are significant differences in degeneration rate in relation to maturation media $(p<0.001)$, both for atmosphere A: $65.51 \pm 7.3,39.63 \pm 7.1$ and $28.19 \pm 6.4$ for media 1,2 and 3 , or atmosphere B: $71.4 \pm 12.2,27.71 \pm 10.0$ and $25.33 \pm 10.2$ respectively. Degeneration rates were lower in atmosphere $\mathrm{B}$ than $\mathrm{A}$ in all maturation media. In any case, it is clear than medium 1 generate higher degeneration rates, followed by medium 2 and medium 3 showed the low rates of degeneration.

Many studies to date have used an atmosphere of $5 \%$ $\mathrm{CO} 2$ in air for canine oocyte maturation $[12,21,22]$, like in other species, but we no found references in the use of $\mathrm{N}_{2}$ for maturation process. Despite the fact that there are several studies with $\mathrm{O}_{2}$ in various species of mammals, revealing that the concentration of $\mathrm{O}_{2}$ inside the uterus and oviducts usually fluctuates in the range of $2-8 \%$ [23], we used $5 \%$ of $\mathrm{O}_{2}$. Silva et al. [15], showed in canine CCs that low $\mathrm{O}_{2}$ tension was efficient in reducing apoptosis, working with $5 \% \mathrm{O}_{2}$ tension level and $5 \% \mathrm{CO}_{2}$ with a media supplemented with FCS, $\mathrm{FSH}, \mathrm{E}_{2}$ and $\mathrm{HCG}$ and high levels of glucose $(5.5 \mathrm{mM})$, obtaining $38.9 \%$ of apoptosis. We obtained degenerated oocyte values of $65.5 \pm 7.3,39.6 \pm 7.1$ and $28.19 \pm 6.4$ for media 1,2 and 3 respectively with $5 \% \mathrm{CO}_{2}$ during maturation, and $71.42 \pm 12.23,27.71 \pm 10.0$ and $25.33 \pm 10.2$ in case of culture with the presence of $\mathrm{O}_{2}$ and $\mathrm{N}_{2}$. In the same conditions, results are comparables, and bitch serum was the worst option, with more degeneration rates in both gasses conditions. The presence of $\mathrm{N}_{2}$ may be beneficial in reduction degeneration rates with the other supplementations. This could be due to the fact that oocyte completes his maturation in oviduct and the requirements may be different to other species in which maturation is completed inside follicle, and in vitro $5 \% \mathrm{CO}_{2}$ is an option for better maturation results.

Other factors susceptible to manipulate in the maturation conditions are supplements. Lopes et al. [24] compared different protein supplementation on maturation media using the standard $5 \% \mathrm{CO}_{2}$ atmosphere: $0.3 \%$ BSA or with $10 \%$ bitch heat inactivated plasma, but not differences between both supplementation groups were found for Met II stage, although DNA fragmentation were higher for BSA group. Respect to bitch serum, there are many options of serum, due to different stages of bitch cycle, but oestrus bitch serum seems to be the best one. Oh et al. reporting supplementing culture medium with $10 \%$ canine oestrous serum get $13.5 \%$ MII stage [25]. However, we reached means of maturation significantly lowest with this supplementation, $4.31 \pm 7.3$ for atmosphere $\mathrm{A}$ and 0 in atmosphere B, with levels of degeneration higher in the second case.

Following ovulation, canine oocytes are also exposed to high $E_{2}$ concentrations in the oviduct, suggesting that $E_{2}$ plays an important role in the meiotic maturation of oocytes. Perhaps EGF regulates oocyte growth, and may be responsible for stimulating nuclear and cytoplasmic maturation.

The best maturation results and lower degeneration rates were obtained in both atmospheres with treatment 3, which include $\mathrm{E}_{2}$ and $\mathrm{EGF}$, aiming to reproduce artificially maturation conditions. Hatoya et al. [26] showed good maturation results with $\mathrm{E}_{2}$ and $\mathrm{EGF}$ supplementation in combination with $\mathrm{FBS}$, with rates of MII higher than in other groups, reaching $8.7 \%$. In the present work, FBS was replaced by BSA and results were similar: $7.97 \pm 2.5$ mean in case of atmosphere A and 9.33 \pm 4.0 mean for atmosphere B. So, environment could improve maturation media influence in these conditions. Although, Songsasen et al. [27, 28] observed that achievement of nuclear oocyte maturation in the dog was not influenced by the oxygen concentration in medium, Silva et al. concluded that it seems that a low level of $\mathrm{O}_{2}(5 \%)$ may be necessary to maintain the viability of canine cumulus and COC cells during IVM [15]. They illustrated the way in which the effect of medium in conjunction with a low $\mathrm{O}_{2}$ tension level positively influences the integrity of cumulus cells, and its coupling with the oocyte and COC viability. In bovine studies, there are results that reflect optimal energy substrates concentrations for maturation media may vary depending on gaseous atmosphere used [29, 30].

\section{CONCLUSIONS}

Although, no good maturation results are raised with any media, the presence of estrous bitch serum seems the worst option. The environment could be a factor affecting the results and modulates the maturation media: atmosphere with $5 \% \mathrm{CO}_{2}, 5 \% \quad \mathrm{O}_{2}$ and $90 \% \quad \mathrm{~N}_{2}$ results in a more favourable habitat for canine oocytes.

\section{CONFLICT OF INTEREST}

The authors confirm that this article content has no conflict of interest.

\section{ACKNOWLEDGEMENTS}

We are grateful to Biotechnology Reproduction Laboratory (INTA Balcarce, Argentine) for allowing us to 
use their laboratories and to veterinaries from Zoonosis Department of Mar del Plata, Argentine.

This study was supported by a grant of Diputación General de Aragón (DGA)

\section{REFERENCES}

[1] Farstad W. Assisted reproductive technology in canid species. Theriogenology 2000; 53: 175-86.

[2] Holst PA, Phemister RD. The prenatal development of the dog: preimplantation events. Biol Reprod 1971; 5: 194-206.

[3] Kim MK, Fibrianto YH, Oh HJ, Jang G, Kim HJ, Lee KS. Effects of estradiol-17beta and progesterone supplementation on in vitro nuclear maturation of canine oocytes. Theriogenology 2005; 63: 1342-53.

[4] Hsu CJ, Holmes SD, Hammond JM. Ovarian epidermal growth factor-like activity. Concentrations in porcine follicular fluid during follicular enlargement. Biochem Biophys Res Commun 1987; 147: 242-7.

[5] Westergaard LG, Andersen CY. Epidermal growth factor (EGF) in human preovulatory follicles. Hum Reprod 1989; 4: 257-60.

[6] Singh B, Rutledge JM, Armstrong DT. Epidermal growth factor and its receptor gene expression and peptide localization in porcine ovarian follicles. Mol Reprod Dev 1995; 40: 391-9.

[7] Lonergan P, Carolan C, Van Langendonckt A, Donnay I, Khatir H, Mermillod P. Role of epidermal growth factor in bovine oocyte maturation and preimplantation embryo development in vitro. Biol Reprod 1996; 54: 1420-9.

[8] Qu J, Nisolle MM, Donnez J. Expression of transforming growth factor-alpha, epidermal growth factor, and epidermal growth factor receptor in follicles of human ovarian tissue before and after cryopreservation. Fertil Steril 2000; 74: 113-21.

[9] Goud PT, Goud AP, Qian C, Laverge H, Van der Elst J, De Sutter $\mathrm{P}$. In vitro maturation of human germinal vesicle stage oocytes: role of cumulus cells and epidermal growth factor in the culture medium. Hum Reprod 1998; 13: 1638-44.

[10] Prochazka R, Srsen V, Nagyova E, Miyano T, Flechon JE. Developmental regulation of effect of epidermal growth factor on porcine oocyte-cumulus cell complexes: nuclear maturation, expansion, and F-actin remodelling. Mol Reprod Dev 2000; 56: 6373.

[11] Kim MK, Fibrianto YH, Oh HJ, Jang G, Kim HJ, Lee KS. Effect of beta-mercaptoethanol or epidermal growth factor supplementation on in vitro maturation of canine oocytes collected from dogs with different stages of the estrus cycle. J Vet Sci 2004; 5: 253-8.

[12] Rota A, Cabianca G. In vitro maturation rates of canine oocytes from anoestrous bitches in simple media. Reprod Nutr Dev 2004; 44: 105-9.

[13] Meister A. Selective modification of glutathione metabolism. Science 1983; 220: 472- 7.

[14] Songsasen N, Wesselowski S, Carpenter J, Wildt D. The ability to achieve meiotic maturation in the dog oocyte is linked to glycolysis and glutamine oxidation. Mol Reprod Dev 2012; 79: 186-96.

[15] Silva AEF, Rodriguez P, Cavalcante LF, Ongaratto F, Rodrigues $\mathrm{BA}$, Rodrigues JL. The influence of oxygen tension on cumulus cells viability of canine COCs matured in high-glucose medium. Reprod Domestic Anim 2009; 44: 259-62.

[16] Luvoni GC, Chigioni S, Allievi E, Macis D. Factors involved in vivo and in vitro maturation of canine oocytes. Theriogenology 2005; 63: 41-59.

[17] Chigioni S, Allievi E, Macis D, Brambilla L, Luvoni G. Evaluation of nuclear morphology of canine oocytes sequentially stained with Hoechst and Orcein. 3rd Annual Congress of European Veterinary Society for Small Animal Reproduction (EVSSAR), Dublin, Ireland 2003; pp. 121-2.

[18] Reynaud K, Chastant-Maillard S, Batard S, Thoumire S, Monget P. IGF system and ovarian folliculogenesis in dog breeds of various sizes: is there a link? J Endocrinol 2010; 206: 85-92.

[19] Agarwal A, Allamaneni S. In: Singh KK, Ed. Oxidative Stress, Disease and Cancer. Imperial College Press: New York, USA 2006; pp. 687-703.

[20] Im GS, Lai L, Liu Z, Hao Y, Wax D, Bonk A, Prather R.S. In vitro development of preimplantation porcine nuclear transfer embryos cultured in different media and gas atmospheres. Theriogenology 2004; 61(6): 1125-35.

[21] Otoi T, ShinT, Kraemer DC, Westhusin MC. Influence of maturation culture period on the development of canine oocytes after in vitro maturation and fertilization. Reprod Fertil Dev 2004; 44: 631-7.

[22] Kempisty B, Woz'na M, Piotrowska H, et al. The expression of genes encoding zona pellucida glycoproteins in canine cumulusoocyte complexes cultured in vitro in media supplemented with progesterone and estradiol. Theriogenology 2012; 77: 684-93.

[23] Gomes SDB, Batista J, Oliveira A, et al. IVF/ICSI outcomes after culture of human embryos at low oxygen tension: a meta-analysis. Reprod Biol Endocrinol 2011; 9: 143.

[24] Lopes G, Alves MG, Carvalho RA, Luvoni GC, Rocha A. DNA fragmentation in canine oocytes after in vitro maturation in TCM199 medium supplemented with different proteins. Theriogenology 2011; 76(7): 1304-12.

[25] Oh HJ, Fibrianto YH, Kim MK, Jang G, Hossein MS, Kim HJ, Kang SK, Lee BC, Hwang WS. Effects of canine serum collected from dogs at different estrous cycle stages on in vitro nuclear maturation of canine oocytes. Zygote 2005; 13(3): 227-32.

[26] Hatoya S, Sugiyama Y, Nishida H, et al. Canine oocyte maturation in culture: Significance of estrogen and EGF receptor gene expression in cumulus cells. Theriogenology 2009; 71: 560-7.

[27] Songsasen N, Yu I, Leibo SP. Effects of maturation media and oxygen concentration on nuclear maturation of canine oocytes. Theriogenology 2001; 55: 494.

[28] Songsasen N, Yu I, Leibo SP. Nuclear maturation of canine oocytes cultured in protein-free media. Mol Reprod Dev 2002; 62(3): 407-15.

[29] Hashimoto S, Minani N, Takakura R, Yamada M, Imai H, Kashima $\mathrm{N}$. Low oxygen tension during in vitro maturation is beneficial for supporting the subsequent development of bovine cumulus- oocyte complexes. Mol Reprod Dev 2000; 57: 353-60.

[30] Oyamada T, Fukui Y. Oxygen tension and medium supplements for in vitro maturation of bovine oocytes cultured individually in a chemical defined medium. J Reprod Dev 2004; 50: 107-17. 